\title{
Formação profissional para atuação em projetos sociais: no foco a formação de professores no "programa Segundo Tempo"
}

\author{
Marynelma Camargo Garanhani* \\ Khaled Omar Mohamad El Tassa**
}

\begin{abstract}
Resumo: O estudo apresenta uma reflexão sobre a formação profissional de professores de Educação Física e/ou Esporte para a atuação em projetos do "Programa Segundo Tempo" (PST) do Ministério do Esporte, coordenado pela Secretaria Nacional de Esporte Educacional (SNEED). Para isso, propõe uma discussão teórica sobre o perfil do professor para uma intervenção profissional em projetos sociais e reflexões sobre a configuração do professor de Educação Física e/ou Esporte para atuar profissionalmente no PST. Para finalizar, comenta alguns desafios da equipe de professores formadores de professores de Educação Física e/ou Esporte para atuarem nos projetos do PST.
\end{abstract}

Palavras-chave: Formação de professores. Educação física. Esporte. Projetos.

\section{INTRODUÇÃo}

Este estudo tem a intenção de discutir e refletir sobre a formação profissional de professores de Educação Física e/ou Esporte para a atuação em projetos do Programa Segundo Tempo ${ }^{1}$ (PST) do Ministério do Esporte, coordenado pela Secretaria Nacional de Esporte Educacional (SNEED). Para isso, organizamos o texto em

\footnotetext{
'Professora Adjunta do Departamento de Educação Física, Universidade Federal do Paraná, Curitiba, PR. E-mail: marynelma@ufpr.br

"Professor Assistente do Departamento de Educação Física. Universidade Estadual do CentroOeste do Paraná ? UNICENTRO, Irati, PR. E-mail: khaledunicentro@hotmail.com

1"O Segundo Tempo é um Programa Estratégico do governo federal que tem por objetivo democratizar o acesso à prática e à cultura do esporte de forma a promover o desenvolvimento integral de crianças, adolescentes e jovens, como fator de formação da cidadania e melhoria da qualidade de vida, prioritariamente daqueles que se encontram em áreas de vulnerabilidade social". (FILGUEIRA; PERIM; OLIVEIRA, 2009, p.8-9).
} 
três temas: o primeiro trata de uma discussão teórica sobre o perfil do professor para uma intervenção profissional em projetos sociais. O segundo sugere reflexões sobre a configuração do professor de Educação Física e/ou Esporte para atuar profissionalmente no PST. E o último comenta os desafios da equipe de professores formadores de professores de Educação Física e/ou Esporte para atuarem nos projetos do PST: as equipes colaboradoras (EC's).

\section{Projetos SOCIAS E A INTERVENÇÃo PROFISSIONAL: UM DESAFIO PARA PROFESSORES}

Os projetos sociais se apresentam como um exercício de cidadania, pois além de envolver as pessoas, em suas vivências cotidianas, levam a uma transposição de barreiras sobre preconceitos, presentes na sociedade, em benefício do outro. Dessa forma, a participação em um projeto social desperta o sentimento de solidariedade e colabora para a conscientização do indivíduo e do papel que ele desempenha no contexto sociocultural e econômico ao qual pertence.

Mas para uma reflexão sobre essa temática, é necessário considerar os sistemas e contextos socioculturais e econômicos que configuram a sociedade, nos dias de hoje. Isso constitui tarefa difícil em função da complexidade e do dinamismo próprios dos avanços científicos e tecnológicos do mundo moderno, acrescidos das demandas sociais que se apresentam atualmente. Demandas que se traduzem na preocupação com riscos sociais, como: criminalidade, tráfico de drogas, prostituição infantil etc, e as necessidades socioeconômicas e educativas das crianças, adolescentes e jovens do nosso país.

Nesse sentido, é necessário que as instituições públicas e privadas apresentem propostas para minimizar os impactos dessas demandas e, consequentemente, garantam ações consistentes e diversificadas para uma intervenção educacional na sociedade. 
Os programas e projetos em âmbito municipal, estadual e federal, que contemplam de forma satisfatória as expectativas e necessidades da população, assumem grande importância, neste cenário, e o profissional professor torna-se uma figura indispensável. Assim, ao entender a educação como a principal ferramenta para minimizar as demandas sociais que diferentes contextos culturais e econômicos de nossa sociedade apresentam, o profissional que concretiza as ações é o professor.

Mas o que é ser professor? E qual é a sua atuação profissional em projetos sociais?

Para responder a esta pergunta recorremos às proposições de Canário (1998) que reconfigura o profissional professsor em quatro dimensões essenciais, na tentativa de contribuir com os debates e discussões sobre a formação de professores.

1) Primeira dimensão: o professor é um analista simbólico.

"Considerar o professor como um analista simbólico significa encará-lo como um solucionador de problemas, em contextos marcados pela complexidade e pela incerteza, e não como alguém capaz de dar as respostas certas a situações previsíveis" (CANÁRIO, 1996, p. 20). Os analistas simbólicos são especialistas em identificar, resolver e mediar problemas. São profissionais de visão sistêmica, que lhes permitem lidar com a complexidade, a experimentação e modos de aprendizagem em exercício. (GARANHANI, 2008).

2) Segunda dimensão: o professor é um artesão.

"Mais do que um reprodutor de práticas o professor é um reinventor de práticas, reconfigurando-as de acordo com as especificidades dos contextos e dos públicos" (CANÁRIO, 1998, 20). Ser professor como artesão é inventar e reinventar práticas que mobilizem saberes provenientes da cultura, acumulados historicamente, e ter a compreensão de que esses se traduzem em saberes pedagógicos para a educação da criança, adolescente e/ou jovem. 
3) Terceira dimensão: o professor é um profissional da relação.

O professor exerce uma atividade profissional marcada pela relação face a face, quase permanente com o aluno, e a natureza desta atividade se define tanto por aquilo que ele sabe, como por aquilo que ele é (GARANHANI, 2008). Segundo Canário (1998, p. 21),

reconhecer que a relação professor-aluno impregna
a totalidade da acção profissional do professor,
implica reconhecer também que os professores,
necessariamente aprendem no contacto com os
alunos e serão melhores professores quanto maior
for a sua capacidade para realizar essa
aprendizagem. O que significa que o estereótipo
tradicional de bom professor reduzido à qualidade
de bom e eficaz transmissor de informações terá de
dar lugar à figura do bom comunicador, definido,
sobretudo, pelas suas qualidades de escuta. (1998,
p.21).

4) Quarta dimensão: o professor é um construtor de sentido.

O professor é mais do que transmissor de informações, ou seja, o professor é um construtor de sentido. Para Canário (1998, p.22) "a importância desta questão decorre do reconhecimento da centralidade do sujeito no processo de aprendizagem, entendido este como a construção de uma 'visão de mundo' (ou seja, de si próprio, da relação com os outros e da relação com a realidade social)".

Assim, as dimensões da docência propostas por Canário (1998) nos mostram uma nova configuração do professor, a qual o torna um profissional indispensável nos projetos sociais. Profissional que poderá contribuir no ensino da complexidade de ser cidadão e as diversas instâncias que materializam essa formação: democrática, social, solidária, igualitária, intercultural e ambiental. Portanto, sua ação em projetos sociais é a de formador ao contribuir com a educação de crianças, adolescentes e jovens que se encontram em situação de risco social. Sua intervenção profissional se traduz em: acesso aos saberes, conceitos e práticas de nossa sociedade que 
poderão se transformar em ferramentas de trabalho, possibilidades educacionais e, por fim, conquistas de autonomia pessoal e profissional das crianças, adolescentes e jovens do nosso país.

Neste cenário, destacamos o Programa Segundo Tempo (PST) proposto pelo Ministério do Esporte. Este programa, sob a coordenação da Secretaria Nacional de Esporte Educacional atende projetos sociais que, por meio de práticas esportivas, colaboram com a educação de crianças, adolescentes e jovens do nosso país. É importante ressaltar que as práticas esportivas ofertadas promovem a inclusão social, o bem-estar físico, a promoção da saúde, o desenvolvimento humano e o exercício da cidadania, sendo que os profissionais responsáveis pelos projetos são professores e acadêmicos (estagiários) de Educação Física e/ou Esporte e áreas afins.

\section{AfORMAÇÃo DE PROFESSORES DE EDUCAÇÃo FísicA PARA ATUAÇÃo EM PROJETOS SOCIAIS: UM DESAFIO PARA O ProgRama SEgundo TEMPO}

Evidências têm revelado que a formação profissional de professores e as políticas públicas que dispomos, nos dias hoje, não tem sido suficientes para garantir o sucesso das ações desses profissionais em projetos sociais (ZEICHNER, 2008). Estas considerações reforçam a idéia de que a formação profissional de professores de Educação Física e/ou Esporte apresenta-se como uma preocupação permanente nas discussões acadêmicas e profissionais.

Cabe ressaltar que um dos grandes problemas evidenciados na intervenção profissional dos professores de Educação Física e/ou Esporte é o distanciamento entre a teoria apresentada na formação universitária e o enfrentamento da realidade do cotidiano, nos espaços de trabalho. As lacunas existentes entre a formação inicial e a intervenção profissional ressaltam a necessidade de pensar uma formação diferenciada. 
Cabe também destacar a importância da aproximação e relação entre a universidade e a comunidade na formação desse profissional. A comunidade, além de fortalecer seus ideais de formação do cidadão, ao aceitar participar de projetos sociais, poderá fornecer à universidade temas importantes a serem problematizados. Já a universidade, ao integrar-se em projetos sociais, permite o redimensionamento da formação inicial próxima ao cotidiano da prática profissional e a atualização para a formação continuada.

Assim, o professor ao elaborar e/ou participar de um projeto social, no qual o foco são as atividades esportivas e de lazer, deverá adquirir, construir e ressignificar saberes, que poderão configurar a docência em Educação Física em torno das dimensões propostas por Canário (1998), ou seja, ser professor de Educação Física, na dimensão analista simbólico, "é muito mais do que conhecer as técnicas das práticas corporais tradicionais: as técnicas das ginásticas, das danças, das lutas, dos jogos e dos esportes. É ter clareza e saber justificar por quais razões essas práticas deverão estar presentes na educação das pessoas". (GARANHANI, 2008, p. 201). Para isso, é necessário que o professor analise simbolicamente os marcadores identitários que configuram os corpos e os comportamentos de seus alunos.

Goellner (2009, p. 73) orienta:

[...] um projeto que se propõe a promover a inclusão social, tal qual o Programa Segundo Tempo, deve, necessariamente, estar atento a questões que vão além das diferenças de classe social, as quais não deixam de ser importantes, mas não são as únicas diferenças a promover a exclusão. Destacam-se, aqui, outros marcadores identitários tais como gênero, geração, raça/etnia, sexualidade, capacidade física, etc., pois, em seu nome, alguns sujeitos são excluídos da prática de atividades corporais e esportivas. Quando isso acontece, estamos diante daquilo que denominamos discriminação, visto que, por vezes, promovemse situações desiguais de acesso e permanência ao 
esporte e ao lazer entre meninos e meninas, homens e mulheres, negros, índios e brancos, crianças, jovens, adultos e velhos, heterossexuais e homossexuais, ricos e pobres, com deficiências, entre outras.

No PST, o professor de Educação Física e/ou Esporte, como um analista simbólico, deverá conhecer a marcas identitárias das crianças, adolescentes e jovens que integram o projeto social de sua responsabilidade. Este procedimento é necessário para que possa selecionar, contextualizar e ressignificar as práticas esportivas que compõem o projeto pedagógico de seu núcleo ${ }^{2}$ e, consequentemente, justificar por que elas serão oferecidas a essa comunidade.

O professor de Educação Física e/ou Esporte deverá ser também um profissional da relação e essa dimensão na atuação docente significa: "estar atento às relações que se vivenciam no processo de ensinar/aprender. Respeitar a individualidade corporal, a diferença de condições pessoais e a diversidade nas formas de se movimentar. É permitir-se vivenciar relações de aprendizagem e refletir sobre saberes que emergem neste processo de educação". (GARANHANI, 2008, p. 202).

Segundo Greco, Silva e Santos (2009) o ensino dos esportes no PST apoia-se numa concepção pedagógica de iniciação esportiva em que joga-se para aprender e aprende-se jogando, ou seja, quando se ensina esporte, pode-se ensinar mais do que o esporte, propriamente dito. Assim, ao relacionar os saberes do esporte com o desenvolvimento da cidadania, estaremos ensinando pelo esporte e, para isso, é necessário que o professor, como um artesão, selecione, organize e desenvolva os conteúdos de sua prática em três dimensões, conforme orienta Darido e Oliveira (2009):

\footnotetext{
${ }^{2}$ Os projetos do PST se organizam em núcleos e estes "visam ocupar o tempo ocioso de crianças, adolescentes e jovens e oferecem, no contraturno escolar (no mínimo três vezes por semana, duas horas por dia em seu modelo- padrão), as atividades esportivas sob a orientação de coordenadores e monitores de Educação Física e/ou Esporte, reforço alimentar e atividades complementares (FILGUEIRA; PERIM; OLIVEIRA, 2009, p. 9).
} 
*dimensão conceitual (o que se deve saber),

*dimensão procedimental (o que se deve fazer) e

*dimensão atitudinal (o que se deve ser).

Com base nessas orientações, o professor, no planejamento de suas práticas esportivas e de lazer, no âmbito do PST, deverá priorizar temas relevantes da Educação Física e/ou Esporte associando-os à realidade vivenciada pelas crianças. Para tanto, a implementação da proposta necessita extrapolar em suas atividades a prática pela prática, com uma ressignificação dos conteúdos para além dos procedimentos, em que é necessário explorar também aspectos relacionados aos conceitos, valores e atitudes. Isso significa "inventar e reinventar com os alunos movimentos com o corpo e estes movimentos deverão proporcionar a (re)configuração de práticas corporais que atendam às especificificidades e necessidades das crianças, jovens e adultos" (GARANHANI, 2008, p. 201). Portanto, o professor artesão é aquele que tem "ousadias de mobilizar elementos pedagógicos e artísticos diante de situações únicas e inesperadas, que levem os alunos a experimentações singulares e significativas" (GARANHANI, 2008, p. 201).

Em síntese, o professor de Educação Física e/ou Esporte do PST deverá ser um artesão na construção e reconstrução de conhecimentos e práticas de movimentos que darão sentidos às experiências esportivas vivenciadas pelos participantes dos projetos. Portanto, é um construtor de sentido e ser professor nesta dimensão significa:

[...] saber mobilizar o aluno para as aprendizagens de movimento corporais. Além da execução de movimentos, mobilizá-lo a compreender que um fundamento do esporte - por exemplo, o toque do voleibol, o drible do basquete, o flick-flack da ginástica - constituem uma linguagem universal. E a aprendizagem desses movimentos nos dá a condição de estabelecer uma comunicação não verbal com qualquer cultura que, também, pratique esses esportes. É também oportunizar ao aluno o conhecimento e a experimentação das mais variadas 
formas de dançar, além de mostrar que cada uma dessas formas tem uma origem sociocultural; proporcionar, ainda, ao aluno vivências de atividades ginásticas com o objetivo de desenvolvimento e formação corporal, mas acima de tudo de conhecimento e conscientização do seu próprio corpo; selecionar e organizar jogos para que os alunos possam viver situações não só de competição, mas também de cooperação. Enfim, é possibilitar aos alunos vivências de aprendizagens de movimentos com o seu corpo pela descoberta, experimentação, compreensão e conscientização e não, simplesmente, pela imitação e repetição [...] (GARANHANI, 2008, p. 202).

Mas, para que isto aconteça o professor deverá:

[...] preocupar-se também com a organização de ambientes de aprendizagens e seleção de atividades que mobilizem a vivência de experiências corporais significativas e que respeitem as características e necessidades das idades; utlizar diversos materiais pedagógicos e que na seleção contemplem os tradicionais, os oficiais, os que estão na moda, os alternativos e se possível os radicais; respeitar as diversas formas de envolvimento de seus alunos nas atividades e valorizá-las, aceitando também as sugestões que eles oferecem de novas formas de aprender. (GARANHANI, 2008, p. 203).

Assim, ser um profissional de Educação Física e/ou Esporte que integre as diferentes dimensões propostas, na docência no PST, é desenvolver uma prática pedagógica atenta à análise símbólica que os grupos sociais expressam em suas marcas identitárias. Para isso, deverá estar disposto a ser um profissional que estabelece relações com as crianças, adolescentes e jovens que frequentam os projetos e, como um artesão, selecione, organize e ofereça práticas esportivas significativas, as quais construam sentidos para suas vidas.

Para concluir, ressaltamos que o profissional de Educação Física e/ou Esporte, com a responsabilidade da docência em projetos sociais, deverá organizar práticas esportivas e de lazer voltadas para o 
desenvolvimento da autonomia e identidade corporal de seus participantes, a socialização e, consequentemente, a ampliação de conhecimentos sobre práticas de movimento que compõem as diferentes manifestações esportivas e artísticas presentes em nossa sociedade.

\section{A ATUAÇÃo de FORMADORES DE PROFESSORES NO PROGRAMA SEGUN- DOTEMPO: OS DESAFIOS DA EQUIPE DE PROFESSORES COLABORADORES (EC's)}

O programa de capacitação desenvolvido no PST tem como um de seus objetivos aprofundar a interação entre os formadores das equipes colaboradoras - EC's (os quais são professores das instituições estaduais e federais públicas de Ensino Superior - IES) com os integrantes das entidades conveniadas ao programa (prefeituras, secretarias, escolas, etc.).

Busca-se, no planejamento e desenvolvimento das ações das EC's para a formação profissional de professores, uma aproximação concisa na organização das temáticas relevantes com a realidade social de inserção dos núcleos do PST. Para tanto, são premissas do trabalho: a interação e o aprofundamento das relações entre os integrantes das EC's e dos núcleos do PST na organização de ações pedagógicas que atendam às demandas da Educação Física/Esportes em projetos sociais, bem como o enfrentamento, em parceria e em sintonia com os professores coordenadores de núcleos do PST, de questões socioculturais presentes na relação ensino e aprendizagem dos alunos integrantes do programa.

A formação é ofertada aos coordenadores de convênio, coordenadores pedagógicos e coordenadores de núcleo, sendo organizada pelas EC's com base nas diretrizes e orientações pedagógicas propostas pela Secretaria Nacional de Esporte Educacional (SNEED). A formação dos acadêmicos-monitores é de responsabilidade da coordenação da entidade conveniada 
As diretrizes e orientações pedagógicas do PST se apresentam como uma forma inovadora de contribuir para uma proposta de Educação Física que atenda às exigências presentes nos projetos sociais. Para isto, propõem-se práticas esportivas interessantes, as quais contribuem para a formação da cidadania, a um público em que as marcas socioculturais e econômicas mais freqüentes são: violência, prostituição, drogas, dificuldades financeiras, desagregação familiar, carência afetiva, etc. Portanto, estas marcas se apresentam como temas para a organização da formação dos professores e constitui um desafio didático-pedagógico para o PST.

No PST, o envolvimento por parte dos professores formadores de professores (EC's), deve contribuir no apoio efetivo para os trabalhos pedagógicos dos professores e acadêmicos-monitores nos núcleos, além de potencializar a reflexão desses profissionais sobre sua responsabilidade como formador de crianças, adolescentes e jovens do nosso país. Portanto, esses formadores (EC's) também devem se configurar nas dimensões propostas por Canário (1998) e, para isso, é necessário serem profissionais que analisem simbolicamente os professores envolvidos na tarefa de desenvolver o PST, nos diferentes núcleos que o compõem.

Assim, como os núcleos do PST apresentam integrantes de diferentes contextos socioculturais e econômicos, os coordenadores e acadêmicos-monitores, responsáveis por eles, também apresentam diferenças, principalmente, no que se refere à formação profissional. Este fato nos faz concluir que implantar pedagogicamente diretrizes educacionais públicas requer um empenho para lidar com diferentes formações, com a falta de experiência profissional e, principalmente, a fragilidade de conhecimentos para concretizar ações pedagógicas. $\mathrm{O}$ formador tem que estar disposto a viver e construir relações de ensino e aprendizagem de caráter integrativo e, para isso, deve ser um profissional da relação.

Alguns professores que participaram de capacitações propostas pela EC's 17 do PST, ao justificar as suas atuações no PST, citaram 
com maior recorrência as palavras: desafio, responsabilidade, comprometimento, ajuda e, principalmente, compromisso. Isto evidenciou uma preocupação com atitudes de realização pessoal na docência em projetos sociais e, consequentemente, a necessidade da relação. A fala de um dos profissionais que participou de uma das capacitações realizadas pela EC's 17 do PST exemplifica estas conclusões: "a cada capacitação os conhecimentos são ampliados e sem ela a prática não prossegue, pois a partir de cada capacitação a realidade passa a ser vista de outra maneira, com maior empenho e compromisso. (Trecho de uma das avaliações da Capacitação da EC's 17- PST)".

Neste cenário, o formador numa relação de integração poderá se apresentar como um artesão, por meio da construção de sentidos para os objetivos e práticas esportivas que o PST propõe. Assim, a atuação dos formadores, além de proporcionar o conhecimento sobre as diretrizes e orientações pedagógicas do PST, também ajuda os professores a contextualizá-las, adaptá-las e ressignificá-las na elaboração de propostas que atendam aos diversos aspectos socioculturais e econômicos, que apresentam os diferentes núcleos do programa. Para isso é necessário não somente uma formação no formato de cursos, os quais no PST são denominados capacitação, mas uma formação em contexto.

Para Oliveira-Formosinho e Kishimoto (2002) a formação em contexto é uma estratégia de integração entre instituição, profissionais e atividades e, para isso é necessário que seja realizada no contexto de trabalho, ou seja, no contexto de ação docente. Para essa autora, a formação se inicia pela identificação de um problema ou de uma necessidade, sendo esta dinâmica a mola propulsora da formação que atende às especificidades que o contexto apresenta, sem se distanciar das diretrizes e orientações pedagógicas do programa em questão.

Assim, com as discussões apresentadas e a proposta da formação em contexto, sugere-se a ampliação da atuação dos professores formadores (EC's) de professores do PST, para além 
dos cursos de capacitação e a supervisão pedagógica. A intenção é contextualizar a formação de professores por meio do levantamento das reais necessidades pedagógicas que as práticas nos diversos núcleos exigem e, com isso, atender às reais necessidades educativas do nosso país. 
Training teachers to perform in social projects - focusing on the 'Second Half Program'

Abstract:The present study presents some thoughts on how to enable physical education and/or sports activities teachers to perform in the "Second Half" Projects - a program under the Ministry of Sports -, coordinated by the National Board of Sports in Education (Secretaria Nacional de Esporte Educacional - SNEED). To attain this aim, a theoretical discussion is proposed about the profile a teacher should have in order to intervene professionally in social projects, and some thoughts are presented on the configuration of the Physical Education and/or Sport Activities teacher so that he/she can perform professionally in "Second Half" Projects. Finally, it comments on some challenges the team of trainers of physical Education and/or Sports activities teachers had to face in the process of preparing those teachers to perform in "Second Half Projects".

Keywords: Teacher training. Physical education. Sports. Projects.

Formación profesional para actuación en proyectos sociales: en foco la formación de profesores en el Programa Segundo Tiempo Resumen:El estudio presenta una reflexión sobre la formación profesional de profesores de Educación Física e/o Deporte para la actuación en proyectos del Programa Segundo Tiempo (PST) del Ministerio del Deporte, coordinado por la Secretaría Nacional de Deporte Educacional (SNEED). Para tanto, propone una discusión teórica sobre el perfil del profesor para una intervención profesional en proyectos sociales y reflexiones sobre la configuración del profesor de Educación Física e/o Deporte para actuar profesionalmente en el PST. Para finalizar, comenta algunos desafíos del equipo de profesores formadores de profesores de Educación Física e/o Deporte para actuar en los proyectos del PST.

Palabras-clave: Formación de profesores. Educación física. Deporte. Proyectos sociales. 


\section{REFERÊNCIAS}

CANÁRIO, Rui. A escola: o lugar onde os professores aprendem. Psicologia da Educação: Revista dos Estudos Pós-graduados em Psicologia da Educação, São Paulo: EDUC, n. 6, p. 9-27, 1. semestre. 1996.

DARIDO, Suraya Cristina; OLIVEIRA, Amauri Aparecido Bássoli de. Procedimentos metodológicos para o Programa Segundo Tempo. In: OLIVEIRA, Amauri Aparecido Bássoli de; PERIM, Gianna Lepre (Org.). Fundamentos pedagógicos do Programa Segundo Tempo: da reflexão à prática. Maringá: EDUEM, 2009.

FILGUEIRA, Julio Cezar Monzú; PERIM, Gianna Lepre; OLIVEIRA, Amauri Aparecido Bássoli de. Apresentação. In: OLIVEIRA, Amauri Aparecido Bássoli de; PERIM, Gianna Lepre (Org.). Fundamentos pedagógicos do Programa Segundo Tempo: da reflexão à prática. Maringá: EDUEM, 2009.

GARANHANI, Marynelma Camargo. O professor de Educação Física no contexto escolar: elementos para reflexões sobre sua função docente. In: SCHMIDT, Maria Auxiliadora et al. (Org.). Diálogos e perspectivas de investigação. ljuí: Unijuí, 2008.

GOELLNER, Silvana Vilodre. Corpo, gênero e sexualidade. In: OLIVEIRA, Amauri Aparecido Bássoli de; PERIM, Gianna Lepre (Org.). Fundamentos pedagógicos do Programa Segundo Tempo: da reflexão à prática. Maringá: EDUEM, 2009.

GRECO, Pablo Juan; SILVA, Siomara A.; SANTOS, Lucídio Rocha. Organização e desenvolvimento pedagógico do Esporte no Programa Segundo Tempo. In: OLIVEIRA, Amauri Aparecido Bássoli de; PERIM, Gianna Lepre (Org). Fundamentos pedagógicos do Programa Segundo Tempo: da reflexão à prática. Maringá: EDUEM, 2009.

OLIVEIRA-FORMOSINHO, Júlia; KISHIMOTO, Tizuko Morchida. Formação em contexto: uma estratégia de integração. São Paulo: Pioneira Thomson Learning, 2002.

ZEICHNER, Kenneth M. M. Uma análise crítica sobre a "reflexão" como conceito estruturante na formação docente. Revista Educação \& Sociedade, Campinas, v. 29 , n. 103 , p. $535-554$, maio/ago. 2008.

Endereço para correspondência:

Universidade Estadual do Centro-Oeste -

Campus de Irati.

Departamento de Educação Física.

Irati, PR. Brasil. PR 153, Km 7, Riozinho.

CEP 84500-000.

Recebido em: 24.04.2013

Aprovado em: 08.06 .2013

Movimento, Porto Alegre, v. 19, n. 04, p. 273-287, out/dez de 2013. 